CUSTOMER ANGER AT PRICE INCREASES, TIME VARIATION IN THE FREQUENCY OF PRICES CHANGES AND MONETARY POLICY

Julio J. Rotemberg

Working Paper 9320 


\title{
CUSTOMER ANGER AT PRICE INCREASES, TIME VARIATION IN THE FREQUENCY OF PRICES CHANGES AND MONETARY POLICY
}

\author{
Julio J. Rotemberg \\ Working Paper 9320 \\ http://www.nber.org/papers/w9320 \\ NATIONAL BUREAU OF ECONOMIC RESEARCH \\ 1050 Massachusetts Avenue \\ Cambridge, MA 02138 \\ November 2002
}

I wish to thank Laura Alfaro, Rafael Di Tella, Huw Pill and Michael Woodford for helpful conversations and the Harvard Business School Division of Research for research support.

(C) 2002 by Julio J. Rotemberg. All rights reserved. Short sections of text, not to exceed two paragraphs, may be quoted without explicit permission provided that full credit, including $\odot$ notice, is given to the source. 
Customer Anger at Price Increases, Time Variation in the Frequency of

Price Changes and Monetary Policy

Julio J. Rotemberg

NBER Working Paper No. 9320

November 2002

JEL No. E3, E4, L2

\title{
$\underline{\text { ABSTRACT }}$
}

While much evidence suggests tha price rigidity is due to a concern with the reaction of customers, price increases do not seem to be typically associated with drastic reduction in purchases. To explain this apparent inconsistency, this paper develops a model where consumers care about the fairness of prices and react negatively only when they become convinced that prices are unfair. This leads to price rigidity, though the implications of the model are not identical to those of existing models of costly price adjustment. In particular, the frequency of price adjustment ought to depend on economy-wide variables observed by consumers. As I show, this has implications for the effects of monetary policy. It can, in particular, explain why inflation does not fall immediately after a monetary tightening.

\author{
Julio J. Rotemberg \\ Graduate School of Business \\ Harvard University, Morgan Hall \\ Soldiers Field \\ Boston, MA 02163 \\ and NBER \\ jrotemberg@hbs.edu
}




\section{Introduction}

Price setters have been asked on repeated occasions to explain why their prices stay constant in nominal terms for periods of time that are vastly longer than the period over which the opportunity cost of production stays constant. The two most common answers received by Hall and Hitch (1939) involved the psychology of customers. They were, in particular, that "conventional price [is] in [the] minds of buyers" and that "Price changes [are] disliked by buyers." Blinder et al (1998) asked price setters about the validity of various theories of sticky prices developed by economists, so they did not ask directly whether price changes were disliked by customers. Nonetheless, a majority of their respondents volunteered that changing prices would "antagonize" or "cause difficulties" with their customers (p. 308).

The simplest model of such negative reactions would posit that the quantity demanded falls dramatically every time a price is increased, perhaps because price increases trigger search as suggested by Stiglitz (1984). However, as I discuss further below, many price increases are associated with only trivial instantaneous reductions in the quantity demanded. It would thus seem that the negative reactions, if they come, come only occasionally. In this paper I propose a model of this type. I suppose that consumers only wish to buy from firms whose prices are "fair" and that price changes trigger a re-evaluation of the firm's fairness. This turns out to be sufficient to imply that firms keep their prices constant at certain times even though most price changes do not lead to customer anger because the firm that increases its price is deemed to have behaved fairly.

A more standard explanation for the existence of periods where prices are fixed involves the assumption that there are non-convex costs of changing prices. These costs are usually motivated by the observation that posting prices involves physical resources so that resources must be spent to change prices by, for example, printing new catalogues (Sheshinski and Weiss 1977). While Levy et. al. (1997) show that the resource costs of changing prices in supermarkets are nontrivial, these administrative costs simply cannot be the whole story.

To see this, Figure 1 shows the prices charged by a supermarket chain for a particular 
product. A striking feature of this series is the recurrence of downwards spikes, short periods where this particular item is "on special". Putting an item on special involves not just labelling it with a different price, but often also involves changing the way it is displayed. After the promotion is over, the supermarket changes the price again, but often chooses exactly the same price as prevailed before the special. Thus, firms appear to have a preference for prices they have charged before even when the resource costs needed to post such prices are the same as those that would be needed to display any other price.

An even more common approach to modelling price rigidity is to suppose that price setters have imperfect information (see Lucas 1972, Mankiw and Reis (2001), Woodford (2002)). However, the prices of commodities are well publicized and move minute by minute while, at the same time, a majority of the economy's prices are set by a small number of individuals. It seems hard to believe that these individuals, who are presumably selected for their competence, would fail to update their beliefs regarding optimal prices for months at a time.

It is worth stressing, however, that the inability of models based on imperfect information by producers to explain this aspect of day-to-day pricing in no way rules out these models as explanations for aggregate movements in economic activity. Indeed, other models of rigid prices that have been applied to aggregate data also seem to face limitations when confronted with microeconomic observations. The model of quadratic costs of price adjustment of Rotemberg (1982), for example, predicts that firms ought to change their prices continuously by small amounts. The Calvo (1983) model assumes periods of price rigidity and thus has the advantage that it is both consistent with this set of micro observations and that it can be calibrated on the basis of information on the frequency of price changes. However, it raises the question of how one should interpret its random trigger for individual price changes. One could interpret it along the lines of Dotsey et. al. (1999) as resulting from i.i.d. randomness in the fixed cost of changing prices. However, it is not clear why the physical costs of changing prices should be particularly random from one period to the next.

One attraction of focusing on how consumers perceive prices is that firms routinely say 
they want their prices to be "fair." As discussed by Hall and Hitch (1939), many firms set prices using the "cost-plus" method which involves starting with variable unit cost, adding the average overhead cost per unit under that assumption that firms produce at "capacity" and, lastly, adding a margin of profit. Oxenfeldt (1951, p. 158) reports that firms justify their margins as follows: "Questionnaire and field surveys indicate the particular acceptance of a margin as 'fair' to be the most important reason for the widespread use of that margin." These managerial concerns with fairness are perfectly mirrored in the answers given by potential customers in the research of Kahneman, Knetch and Thaler (1986). They asked students what prices they would and would not regard as fair. Their basic conclusion is that price increases due exclusively to changes in demand, e.g. increases in the price of snow shovels during a snowstorm, were deemed to be unfair while increases in prices due to cost increases were deemed fair.

Interestingly, marketing experts have long bemoaned the tendency of firms to set prices with too much regard for costs. For example, after noting that a survey of U.S. exporters reveals that $70 \%$ of them set their prices using the cost-plus method, Dolan and Simon (1996, p.37-38) say "It is foolish not to consider the demand side in setting prices... In spite of its popularity in practice, cost-plus pricing is not an acceptable method for the power-pricer." Yet, in discussing why sellers prefer cost-plus to what he calls "flexible markup pricing," Oxenfeldt (1951, p. 177) says "The strong ethical basis for cost-plus pricing is lost when margins vary according to conditions of demand. Flexible markup pricing would take on the motivation of 'charge as much as the market will bear'".

When managers express their desire to charge fair prices, they may well be concerned with the way consumers perceive these prices. In many of the instances where firms change the terms on which they offer their products they also try to manage these consumer perceptions. For example, many firms told Blinder at al (1998) that they preferred to change other features of their product rather than change the prices themselves. One standard way of doing this, which is often discussed in the "Selling It" column of Consumer Reports, is to reduce the quantity of valuable ingredients in a package. For example, in the October 1994 issue of this 
publication, it is reported that Minute Maid significantly reduced the concentration of its 12 oz. can of Raspberry Lemonade while keeping the price constant. A company representative explained that this was due to cost increases and that "Otherwise, we would have had to charge more."

A perhaps even more insidious version of this is to lower the quality while lowering the price by less than the resulting cost reduction. The October 1994 issue of Consumer Reports reports an example of this as well. It discusses a change in the design of the packages for Gütterman thread. The company made its plastic spools fatter so that, when filled with 110 yards of thread, they would have the same outside dimensions than a previous version which included 220 yards of thread. The price of the newer version was $\$ 1.25$ while the previous one was $\$ 1.45$.

These examples might be seen as simple attempts to move along consumers' demand functions by preventing them from noticing that the price has increased (or that the effective quantity bought has declined). However no equivalent incentive exists for masking price declines with quality improvements. Yet, Oxenfeld (1951) reports that Whitman's boxed chocolates increased its quality but did not reduce its price in the entire Great Depression. The President of the company declared afterwards "Time has proved the wisdom of this procedure. ... For many firms have found it difficult to increase their prices again once they had been reduced" (quoted in Oxenfeldt, 1951, p. 190).

This is a puzzling statement from the point of view of demand management for the following reason. Suppose that the increased sales when a price is reduced are matched by an equal sales decline when the price is subsequently raised and brought back to its original level. A firm that masks both its price decline and its subsequent increase then experiences fewer changes in sales than one that makes its price changes explicit. But, if cost reductions are the cause of the initial masked price cut, it would seem that profits would increase by more if the firm cut its price explicitly so that its sales would rise while its costs were low. A more straightforward interpretation of this statement by Whitman's President is that price increases lead to negative customer reactions that go beyond reductions of sales along a 
well-behaved demand curve.

My theory of price rigidity hinges on the assumption that consumers use nominal price changes as a trigger for reflection about the attitudes of producers. This fits with the suggestion that firms ought to try to "improve" their product when they raise prices. Miller (1976 p. 23) makes this suggestion to restaurants as a way to overcome customer resistance when printing a menu with higher prices. He recommends adding something (like potato chips) "to a standard item and creat[ing] a new package that includes the standard but can be sold for a slightly higher price".

It is worth noting that I am giving consumers a "rule of thumb" when I suppose that they rethink the fairness of their suppliers. In the absence of computation costs, more frequent assessments of fairness might be optimal. However, if reflection about the attitudes of producers is costly, consumers will seek to economize on this type of analysis and will only carry out the required computations when conditions change noticeably.

Interestingly, this model can provide a rationale for the random price changes in Calvo (1983). Consumers' evaluation of the fairness of a price-changing firm depends on their information and this information evolves randomly over time. Thus, there may be periods where a firm is particularly likely to face stiff resistance to price increases and others where much lower resistance is expected. A firm with some information about the likely reactions of its consumers would obviously choose to raise its prices in the latter. Thus, the random receipt of information by consumers may rationalize the random price changes assumed by Calvo (1983).

One difference with the Calvo (1983) model, however, is that price changes ought to be more frequent when the macroeconomic environment suggests that these price changes are fair. Thus, for example, high inflation in the past might convince consumers that costs are likely to have increased and thus may make price increases easier to sustain. This type of reasoning leads to two reasons why contractionary monetary policies may have only a negligible impact on current inflation, with most of the reduction in inflation being observed sometime after interest rates are increased. 
I model the first of these reasons explicitly. A contractionary monetary policy typically reduces the price that a price changing firm would wish to charge because the reduction in demand tends to lower marginal cost. This can, paradoxically, increase the frequency of firms changing prices since the price change that firms now desire has just become more palatable. If the typical firm that changes its prices actually raises them (because the firm operates in an environment of steady inflation), the increased frequency of price adjustment can offset the decline in the price chosen by those firms that change their prices. There is also a second reason for an increase in the frequency of price adjustment in the immediate aftermath of a monetary contraction, though I do not model this explicitly. This is that such a shock makes firms realize that price increases will become less palatable once inflation slows down. This acts as an incentive to raise price before inflation falls, and thereby postpones the onset of low inflation.

The paper proceeds as follows. In the next section I present some evidence on the effects of price increases. The issue I address is whether consumer "resistance" to price increases boils down to a precipitous fall in demand when prices is increased. Insofar as sales do not fall sharply every time prices are raised, the model I propose in the subsequent section is more attractive. The reason is that this model involves the possibility of sharp drops in sales if consumers feel the price increase is unfair but, most of the time, firms will choose price changes that pass muster with their customers.

Section 3 presents my model of consumer reactions to price increases. Section 4 turns to macroeconomic considerations by discussing a general equilibrium model with random price changes where the frequency of price changes can depend on observable economic variables. Section 5 then analyzes how this model behaves in response to monetary policy shocks and Section 6 concludes.

\section{What happens when prices are increased}

Close observation of what happens to firms that change prices is likely to contain important information about the causes of price rigidity. For this reason, I start by studying 
some features of the the scanner data from Dominick's Fine Foods. ${ }^{1}$ These data contain weekly transactions data on price, sales and acquisition cost for a multitude of supermarket items. The data cover several of Dominick's stores and pertains to the period that goes from September 1989 to May 1997. The prices for many of these items alternate between "regular" prices and "specials". A typical example of this pattern is provided in Figure 1, which plots the retail prices as well as the acquisition costs (averaged over stores) for the 16 oz. package of Nabisco Premium Saltines over the 380 weeks for which data are available. As can be seen in this Figure, the "regular" price of this item was changed 5 times. Within each period during which any particular regular price prevailed, there were several subperiods where the item was "on special" and was sold at a lower price. The Figure also shows that the acquisition cost varies closely with the retail price, from which it follows that the manufacturer is closely involved in most (if not necessarily all) decisions to change the retail price of this product.

The price that is "sticky" in this Figure is the "regular" price and it is thus of particular interest to study the effects of changes in this price. Before doing so, it is worth mentioning that total sales of this item are significantly larger during the weeks that the item is on "special." This is consistent with the findings of Hendel and Nevo (2002). Large increases in sales during specials are easy to rationalize, since Saltines are storable at least to some extent. Thus, a temporary reduction in price not only encourages more current consumption but also encourages consumer to purchase extra units for future use. In addition, "specials" may induce purchases from consumers who do not typically buy the item, particularly because specials are often displayed prominently in the supermarket.

One important feature of "specials" is that supermarkets rarely put similar products offered by competing producers on "special" at the same time. An obvious question that arises when studying changes in "regular" prices is whether competitors synchronize these changes. I thus discuss briefly the range of related products sold by Dominick's. First,

\footnotetext{
${ }^{1}$ The data were obtained from http://gsbwww.uchicago.edu/research/mkt/Databases/DFF/Files.html. For a longer description, see Barsky et. al. (2002).
} 
Nabisco itself produces several similar products including Saltines with either no or low salt, as well as packages in different sizes. The 16oz. package of Nabisco Premium Saltines is the most popular of these, but the other items with the same weight sell almost always for exactly the same price. Thus, this item seems representative of the Nabisco offerings of this product class. Several other manufacturers produce saltines, though only three additional brands were sold by Dominick's for most of the duration of this particular sample. One of these is the Dominick's brand of Saltines, a second one is sold under the brand of Salerno. In addition, Dominick's carried both regular and low salt saltines sold under the Keebler brand. Since the two Keebler products were almost always sold for the same price, I focus on Keebler's regular product, which was more popular. The sales of Keebler and Dominick's own brand of saltines were comparable, though considerably smaller than those of Nabisco's brand. The sales under the Salerno brand were somewhat smaller that those of either the Keebler or Dominick's brand.

These four brands did not synchronize the timing of their "regular" prices changes. Nabisco's Premium Saltines were first sold for $\$ 1.79, \$ 1.89, \$ 1.99, \$ 2.19$ and $\$ 2.29$ in weeks 21, 108, 142, 327 and 364 respectively. $^{2}$ Only the first of these price changes was accompanied by changes in the regular prices of any of the main competitors. Nabisco acted as a price leader in that competitors tended to follow its price increases, but with some delay. Salerno, for example, followed the third, fourth and fifth increases with price increases in weeks 149, 339 and 373 respectively. Keebler followed the second and fourth Nabisco increases with changes in weeks 116 and 338, while Dominick's had a price change in week 333 and thereby followed Nabisco's fourth increase. The first Nabisco price increase was unusual because Keebler also raised its price to $\$ 1.78$ in week 21 .

Before proceeding to the discussion of the changes in quantity that accompanied these price increases, it is worth noting that the first three of these regular price increases were

\footnotetext{
${ }^{2}$ In giving the weeks in which various events took place, I use the nomenclature for "weeks" in the Dominick's data base. This does not coincide perfectly with the way weeks are displayed in Figure 1 because data is not available for certain weeks.
} 
preceded by having Nabisco's Premium Saltines on special. ${ }^{3}$ The previous regular price been charged in contiguous weeks ending in week 16, 104 and 137 respectively. To get a sense of what happened to Nabisco's sales after regular price increases, I compare the average number of boxes sold in the first three weeks of the new price to the average sold in the last contiguous stretch where the previous regular price was charged to customers. ${ }^{4}$ This comparison might overstate the declines in sales brought on by the regular price increase if the intervening weeks where the product was on special led customers to stock up. In any event, the last two increases are free from this problem.

Table 1

\section{Changes in Nabisco Sales when Regular Price Rises}

\begin{tabular}{|c|c|c|c|c|}
\hline & $\begin{array}{c}\text { Weeks of } \\
\text { "old" price }\end{array}$ & $\begin{array}{c}\text { Weeks of } \\
\text { "new price }\end{array}$ & $\begin{array}{c}\text { \% change } \\
\text { in price }\end{array}$ & $\begin{array}{c}\text { \% change in } \\
\text { boxes sold }\end{array}$ \\
\hline 1 & $13-16$ & $21-23$ & 16.3 & -.12 \\
2 & $89-104$ & $108-110$ & 5.6 & 23.4 \\
3 & $132-137$ & $142-144$ & 5.3 & -18.3 \\
4 & $320-325$ & $327-329$ & 10.0 & -4.6 \\
5 & $356-362$ & $364-366$ & 4.6 & 23 \\
\hline
\end{tabular}

The results of this comparison are presented in Table 1, which also gives the weeks of "old" and "new" prices that I compare, as well as the relevant percent change in regular prices. The table shows that, on two occasions, sales actually rise dramatically right after the regular price is increased while only once does the quantity decline significantly. While generalizing from this small set of numbers is precarious, it seems fair to say that regular price increases are not necessarily followed by big reductions in the quantity demanded, even if competitors do not match the price increases.

\footnotetext{
${ }^{3}$ This suggests that the fixed costs of physically posting new prices may play some role in the joint timing of promotions and regular price changes. When an item goes back to being sold at a regular price, the store incurs costs to change what it displays and some of these costs must be incurred again if the store later changes the regular price of the item. There are thus some cost savings in moving directly from the promotional price to a new regular price.

${ }^{4}$ I use averages because sales vary considerably from week to week. This is what leads me to use the entire set of contiguous weeks where the "old" regular price was last charged. I only use the first three weeks with the "new" price to capture the effect of price changes. The results are not very sensitive to using only the first full week with the new price or just the last three contiguous weeks with the "old" price.
} 
One potential interpretation of these observations is that Nabisco has information about the weeks in which demand is higher and raises its price in those weeks. This cannot be ruled out. However, forecasting week-to-week demand changes in this industry seems difficult. Weekly sales are quite volatile even in periods with constant prices. For example, while all four major brands kept their price constant from week 33 to week 34, Nabisco's sales fell by $21 \%$ from the former to the latter. Moreover, since the four firms do not synchronize their price movements, one would only be able to believe that Nabisco is timing its price changes to coincide with demand variations if one also believed that the relative demand for the different brands is predictable.

If one accepts that prices are not tailored to significant brand-specific demand variations, the evidence of Table 1 would seem to rule out theories where demand is kinked at the "old" price. Since competitive products whose price has remained constant are available nearby, the evidence suggests that individuals do not respond to price increases by immediately embarking on a search for a better deal. The evidence also seems inconsistent with a setting where customers feel that any price increase is sufficiently unfair as to lead customers to reduce their purchases. Rather it suggests that, insofar as customers react badly to price increases, they do so either with a delay or only occasionally.

Given that some price increases elicit strenuous objections right away, it seems more straightforward to suppose that consumers only react with anger on certain occasions. Moreover, the strenuous reactions that do occur appear to catch price setters by surprise. Consider, for example, the reaction to those stores that raised their prices in the aftermath of the earthquake that hit the Los Angeles area in January 1994. Some of these stores were visited by activists and threatened with boycotts (L.A. Times, January 30, 1994). The consumer reaction was so vociferous that Southland Corp. terminated its franchise agreement with several 7-Eleven franchisees who raised prices during the episode (The Orange County Register, 23 January 1994). The hypothesis that franchisees expected this particular reaction does not seem particularly plausible.

Many consumers have also been angry at European stores for "rounding up" when con- 
verting their prices to euro's. The extent to which this behavior actually raised inflation is in dispute. Nonetheless, some of the complaints have been loud. In Greece, in particular, consumer groups successfully called for a mass boycott of stores in early September 2002 to protest the price gouging associated with the introduction of the euro (Reuters, September 2, 2002).

These violent reactions in dramatic historical episodes still leave open the question of whether the typical firm that changes its price faces a significant probability of consumer revolt. The evidence of Table 1 makes it clear that such revolts are not commonplace and is open to at least two interpretations. In the first, firms have good information about consumer reactions and change prices only when they feel the probability of a negative consumer reactions is particularly low. In the second, firms know relatively little about the price that will trigger consumer anger and price conservatively so that the likelihood of such a reaction remains low. The model I develop in the next section can accommodate both of these possibilities.

\section{A One-period model with fairness concerns}

In this section I consider a model where a firm must choose its price in the "last period" of a relationship with consumers. As usual, consumers derive utility from purchasing a good which a firm finds costly to produce. I model these standard components of the relationship by supposing that there is a unit mass of consumers which obtain utility $U(x)$ from consuming $x$ units of the good. At the same time, their utility is linear in the real income that is left over after paying for the $x$ units of the good that they buy. This means that the "material payoffs" of consumers, i.e. their utility function leaving aside aside fairness concerns is

$$
\Omega=U(x)+Y-x \frac{P_{t}}{\bar{P}_{t}} .
$$

The maximization of this utility would lead consumers to purchase a quantity $x$ that satisfies

$$
U^{\prime}(x)=\frac{P_{t}}{\bar{P}_{t}}
$$


where primes denote derivatives. Since the supermarket data suggests that manufacturers are at least partly responsible for the rigidity of prices, I simply consider the pricing decision of a producer. I thus analyze a single monopolistic producer whose nominal cost of production equals to $c(x)$ and suppose that profits from sales give the producer a utility of

$$
V\left(\frac{x P_{t}-c(x)}{\bar{P}_{t}}\right) .
$$

I let the producer set his price first and then let consumers decide how much to purchase. Absent fairness concerns, the optimal price satisfies

$$
P_{t}\left(1-\frac{1}{\epsilon_{t}}\right)=c_{t}^{\prime} \quad \epsilon_{t}=-\frac{x \bar{P}_{t}}{P_{t} U^{\prime \prime}}
$$

where $\epsilon_{t}$ is the elasticity of demand at $t$.

I now consider the actions of a consumer concerned with fairness. A pioneering approach to modelling these concerns is provided by Rabin (1993). His model of fairness involves three key ingredients. These are a definition of "kindness", a definition of "equitable payoffs" and a specification of preferences that depend on both one's own kindness and the kindness one expects from the person one is dealing with. He measures the expected kindness of the second player towards the first by the difference between the payoffs that the first expects to receive from the second and the payoffs that it would "equitable" for the second to give to the first. He then defines equitable payoffs as being equal to the average of the highest and the lowest payoffs the second agent can give to the first under the assumption that the player acts efficiently. Lastly, he supposes that agents maximize the sum of their own material payoffs and the product of their own kindness times the kindness they expect to receive from the other agent. Thus, if the first agent expects the second to give the first a payoff that is higher than the "equitable" payoff, the first agent seeks to raise the second agent's payoff above that agent's equitable payoff. ${ }^{5}$

While my approach is in the spirit of Rabin (1993), it differs in some respects. In particular, I suppose that consumers view firms as fair when they feel that firms act altruistically.

\footnotetext{
${ }^{5}$ For an extension of the Rabin (1993) model to dynamic games, see Falk and Fischbacher (2000) and Dufwenberg and Kirchsteiger (2001).
} 
In particular, I suppose that consumers expect the firm to maximize

$$
V\left(\frac{x P_{t}-c(x)}{\bar{P}_{t}}+\lambda_{f} \Omega\right) .
$$

This is not inconsistent with pure profit maximization since $\lambda_{f}$ can be zero. I further suppose that consumers have a "psychological utility function" given by

$$
\Omega-\lambda_{c} \psi\left(\hat{\lambda}_{f}\right)\left[V\left(\frac{x P_{t}-c(x)}{\bar{P}_{t}}\right)-V_{o}\right]
$$

where $V_{o}$ is the value of $V$ without the consumer's purchase, $\lambda_{c}$ is an arbitrarily large number and $\psi$ is a function of the consumer's perception of the altruism of the firm. ${ }^{6}$ I suppose this function is a step function which equals zero if the consumer cannot reject the hypothesis that the firms $\lambda_{f}$ equals $\bar{\lambda}$ against the alternative that it equals zero. If, instead, the consumer is able to reject the hypothesis that $\lambda_{f}=\bar{\lambda}$, then the function $\psi$ equals one. This means that, in this case, the consumer stops his purchases.

While my approach to fairness is quite similar to Rabin's (1993) in its use of a psychological utility function that seeks to reward like with like, there are some differences in the two specifications. From the point of view of generating price rigidity, one of the key differences is my supposition that the psychological utility function is highly nonlinear. In particular, I suppose that consumers have a neutral attitude towards firm profits in a broad set of circumstances. Positive utility for punishing a firm arises only if consumers feel the firm has behaved in a demonstrably egregious manner. This specification predicts that consumer reactions will be subject to threshold effects, where consumers react only to what they perceive to be extreme cases. When they do react, on the other hand, their reactions are strong. Casual observation suggests that this fits the reactions of consumers somewhat better than the supposition that consumers react in a "continuous" way to bad behavior by

\footnotetext{
${ }^{6}$ In this paper, I consider only altruism of the firm towards consumers. However, corporations also seek to appear "corporately responsible" by engaging in charitable activities. Moreover Campbell (1999) provides questionnaire evidence that people's perception of the fairness of raising the price of a doll whose demand is high just before Christmas depends on whether the proceeds will go to charity or whether they will be kept by the store. Thus, consumers may also refrain from punishing firms that are altruistic towards people other than the consumers themselves.
} 
the firm. ${ }^{7}$ It is much more common to hear calls for complete boycotts than calls for small reductions in the purchases from particular firms, for example.

A second difference with Rabin's (1993) analysis is that he supposes that each player knows both the preferences and the opportunities available to the other. In the case of consumers, it is not plausible to suppose that their information regarding their supplier's circumstances is very good. I have thus cast the analysis in parametric terms, consumers use their information to estimate and test hypotheses about the value of one parameter. The use of an altruism parameter seems particularly straightforward and has the advantage that the parameter remains meaningful even if essentially nothing is known about the firm.

I now analyze the interaction between an altruistic firm and consumers concerned with the firm's fairness. Suppose first that this relationship exists for only one period so that there is no history before $t$. When faced with a price $P_{t}$, consumers must decide whether $\lambda_{f}$ equals $\bar{\lambda}$ or not. Taking into account (2), consumers suppose that a firm with an altruism parameter equal to $\lambda_{f}$ maximizes

$$
V\left(x U^{\prime}-\frac{c(x)}{\bar{P}_{t}}+\lambda_{f}\left[U(x)-x U^{\prime}\right]\right) .
$$

The first order condition for this problem is

$$
P_{t}\left(1-\frac{1-\lambda_{f}}{\epsilon_{t}}\right)=c_{t}^{\prime} .
$$

Not surprisingly, this involves a lower price the higher is the altruism parameter $\lambda_{f}$. The competitive limit is approached as $\lambda_{f}$ tends to 1 .

In practice, consumers are unlikely to have perfect information about either $c^{\prime}$ or $\epsilon$. For simplicity, I leave aside the latter uncertainty for the moment and focus just on uncertainty about $c^{\prime}$. In particular, I suppose that consumers have a subjective p.d.f for $c^{\prime}$ given by $F\left(c^{\prime}\right)$. Given (8), consumers expect $P_{t}\left(1-\frac{1-\lambda_{f}}{\epsilon_{t}}\right)$ to inherit this density function. This means that, consumers can reject the hypothesis that $\lambda_{f}=\bar{\lambda}$ at the usual $95 \%$ confidence level if

$$
F\left[P_{t}\left(1-\frac{1-\bar{\lambda}}{\epsilon_{t}}\right)\right] \geq .95 .
$$

\footnotetext{
7 "Discontinuous" reactions of this type also characterize relationships between firms and workers. See Rotemberg (2003) for a discussion.
} 
Let $\tilde{P}$ represent the price that satisfies this relationship with equality. The firm has a p.d.f. over $\tilde{P}$ given by $G$. This p.d.f. is a step function if the firm knows the true value of $\tilde{P}$. For an arbitrary $G$, the firm sets $P_{t}$ to maximize

$$
\left[1-G\left(P_{t}\right)\right] V\left(\frac{P_{t} x-c(x)}{\bar{P}_{t}}+\lambda_{f}\left[U(x)-x \frac{P_{t}}{\bar{P}_{t}}\right]\right) .
$$

The first order condition for this problem is

$$
[1-G(P)] \frac{V^{\prime}}{U^{\prime \prime} \bar{P}_{t}}\left[P_{t}\left(1-\frac{1-\lambda_{f}}{\epsilon_{t}}\right)-c_{t}^{\prime}\right]-g(P) V\left(\frac{P_{t} x-c(x)}{\bar{P}_{t}}+\lambda_{f}\left[U(x)-x \frac{P_{t}}{\bar{P}_{t}}\right]\right) \leq 0 .
$$

In the case where the $P_{t}$ which solves (8) has the property that $G\left(P_{t}\right)=0$, the solution to this first order condition is given by (8) itself and this is also the optimal price. Now suppose that the price that satisfies (8) does not satisfy (10) because $G\left(P_{t}\right)$ is positive at the price that satisfies (8). There are then two cases to consider. In the first, the price that maximizes (9), $P^{*}$, is interior so that (10) is satisfied as an equality at this price. In the second, the price that maximizes (9) is the price $P$ that satisfies $G(P)=0$ and thus guarantees that consumers regard this price as fair. This second solution applies when $g(P)$ is sufficiently large at the $P$ that ensures that $G(P)=0$ that $(10)$ holds as an inequality at this price.

This model can justify price rigidity from one period to the next even if one supposes that the optimum is of this last type (perhaps because $G$ is a step function at $\tilde{P}$ ). However, one would then have to imagine that $\tilde{P}$ is perfectly rigid over time. This latter condition is not particularly plausible, since consumers are bombarded with information about the economy on a daily basis so they ought to update their distribution of $c^{\prime}$ from one day to the next.

A more plausible model of price rigidity follows if one assumes that consumers do not revise their opinion about the firm's altruism until the firm changes its price. While I do not derive conditions under which this is optimal for consumers, it fits with Kahneman, Knetsch and Thaler (1986) who suppose that an action is regarded as fair if it is better, or at least not worse than a reference action. For the most part, like Rabin (1994), they see actions as fair if they somehow balance the interests of the two parties. But, Kahneman, Knetsch and Thaler (1986) also assert that reference actions are often dictated by the past. According to them, 
changes in conditions including reductions in wages and increases in prices are regarded as unfair unless it is common knowledge that the firm who imposes these changes would suffer greatly without taking these actions.

One reason why consumers may not revise the fairness of the prices they pay if these are identical in nominal terms to those that they have paid in the past is that this rule of thumb saves on costs of computation. Moreover, in the presence of a positive level of trend inflation firms that keep their nominal prices constant at $t$ do tend to offer consumers a better deal than they did at $t-1$. Thus, this rule of thumb may not be very costly to consumers. A second reason for consumers to refrain from re-evaluating the fairness of a firm's price when this price remains constant is that consumers may believe the firm has large administrative costs of changing prices. If consumers had such a belief, they would not change their estimate of $\lambda_{f}$ even if the firm kept its price constant under a broad range of circumstances.

Suppose that economic conditions change from $t-1$ to $t$, so the firm contemplates a change in its price. There are now two illuminating extreme cases to consider. In the first, consumers have no memory of past costs. Thus, they can only compare their current subjective p.d.f. of costs to the current price as above. Knowledge of the past price may be helpful to consumers in this setting, but only insofar as it contains information about the firm's current costs.

If the price at $t$ that satisfies (8) also satisfies (10) because $G\left(P_{t}\right)=0$, the firm chooses its first best action in spite of the customers scrutiny of the firm's altruism. Indeed, in this case, there is no reason for the firm to choose to repeat its earlier price. Now suppose that the price $P$ that satisfies $(8)$ has the property that $G(P)>0$. The firm now keeps its price equal to $P_{t-1}$, its price in the previous period, if the price that maximizes (9) (which is below the price that satisfies (8)) is lower than $P_{t-1}$. Keeping the price constant leads to a price which is closer to the firm's unconstrained optimum without creating any risk of customer complaints.

This logic can explain downwards price rigidity, where costs fall but price stays constant because the resulting high profits are not so visible that they lead to cries of unfairness. 
Obviously, if costs fall enough and consumers are not aware of it, the firm may find that the price that maximizes its true objective function (7) now satisfies (10). Price would then fall, but the fall would be less than proportional to the fall in costs even if the elasticity of demand were constant. ${ }^{8}$

Suppose that, instead, the price that maximizes (9) is above $P_{t-1}$, so that prices would be expected to rise. If the price that maximizes (9) is the price that satisfies $G(P)=0$, the firm should increase its price. The reason is that it thereby increases the value of its objective function without increasing the probability of a consumer revolt. In this case the price is not rigid in the sense of staying constant. However, the firm is being prevented from charging the price it most would like to charge by its fear of consumer reactions.

On the other hand, keeping the price constant is good for the firm if the optimum is interior and the price that satisfies $(10), P^{*}$, is sufficiently close to $P_{t-1}$. By keeping the price constant, the owner gets $V\left(P_{t-1}\right)$ while he gets $\left[1-G\left(P_{t}^{*}\right)\right] V\left(P_{t}^{*}\right)$ if he raises it to $P^{*}$. Since $G\left(P^{*}\right)>0$ the latter can be less than the former. Thus, fear of consumer reevaluation of the firm's fairness can act as a "fixed" cost of price changes that keeps firm prices constant. What makes the model differ from one with a simple fixed cost, however, is that the magnitude of the price change matters as well. This fits with the evidence of Zbaracki et al (2002) who report that salesmen are much more worried about negative reactions to large price increases than they are about small ones.

Consumers are particularly likely to react to large price changes, as opposed to high levels of prices if they have a diffuse prior about the level of $c_{t}^{\prime}$ but have a more precise estimate of the percent change in $c^{\prime}$ from $t-1$ to $t$. This case would seem quite relevant because relatively accurate estimates of the percent change in costs would seem easier to obtain than accurate measures of cost levels. Under constant returns to scale, the percent change in cost equals the inner product of the vector of cost shares with the vector of percent changes in the prices of individual factors. Such an estimate is thus obtainable even if individuals do

\footnotetext{
${ }^{8}$ This logic might explain the widening of profit margins for U.S. coffee distributors as the wholesale price of coffee fell dramatically between 1997 and 2002. See Wall Street Journal, July 8, 2002 for a brief discussion of the relevant facts.
} 
not have access to information about total costs and total revenues. Regarding firms as fair if they price according to (8) with $\lambda_{f}=\bar{\lambda}$, consumers expect the percent change in the price $d P / P$ to equal

$$
\frac{d P}{P}=\frac{d c^{\prime}}{c^{\prime}}-\frac{1-\bar{\lambda}}{\epsilon-1+\bar{\lambda}} \frac{d \epsilon}{\epsilon} .
$$

For a given elasticity of demand, prices are expected to rise by the same amount, namely the percent change in marginal cost regardless of the level of firm altruism. However, changes in $\epsilon$ are expected to have a larger effect if the firm is selfish than if $\lambda_{f}=\bar{\lambda}$. Thus, large differences between the rate of change of prices and the rate of change of costs lead consumers to reject the hypothesis that firm's altruism parameter equals $\bar{\lambda}$ and, according to my model, lead to a cessation of purchases. Supposing once again that consumers only compute whether the firm is being fair when the firm changes its prices, the firm will tend to keep its price constant if its optimal price at $t, P_{t}^{*}$ is close to its inherited price $P_{t-1}$.

While the model rationalizes price rigidity in some circumstances, its precise implications for dynamic pricing depend on the way consumers update their beliefs about $\tilde{P}$. A thorough analysis of these beliefs is beyond the scope of this paper. It is worth noting, however, that the benefit that consumers derive from good information about $c^{\prime}$ may be relatively low. It may thus be possible for consumers to have fairly poor information about the price the firm would charge if its true altruism parameter were $\bar{\lambda}$.

Out of all the bits of information available about changes in $c^{\prime}$, consumers presumably only observe a subset. Thus, their estimates of how a fair price ought to vary could easily be "biased" from the point of view of more informed observers. While firms are likely to be much better informed, they may suffer from limited credibility when they try to convey their information to consumers. This is likely to be particularly true if consumers are not convinced of the firm's altruism.

In what follows I do not explicitly model the way consumers update their information. I suppose instead that consumer beliefs are random functions of the true state of nature and that firms have some information about these beliefs. I use this approach to study the aggregate consequences of potential anger over price changes. 


\section{A Multi-period General Equilibrium Model}

I consider a setting where the beliefs of consumers about what constitutes fair pricing for any given firm vary from period to period and from firm to firm (even though all firms are symmetric). The problem is considerably simplified by supposing that each firm knows what changes in prices its own consumers would regard as fair while also supposing that changing a price when consumers see this as unfair leads to prohibitive losses in profits. This means that firms only change their prices when they know that consumers will find this acceptable.

I suppose that, for each firm, the probability that any price increase at $t$ will be regarded as unfair is $\alpha_{t}$. With the complementary probability $\left(1-\alpha_{t}\right)$, any price increase will be deemed to be fair. With a sufficiently large level of steady state inflation, firms do not ever find it optimal to lower their prices in my setting. It is then unimportant to understand how consumers react to price decreases. ${ }^{9}$ This setting leads to a straightforward generalization of Calvo (1983), since firms change their prices with probability $\alpha_{t}$. The only difference is that he considers the case where $\alpha_{t}$ is constant. For reasons that I discuss below, it seems more natural to imagine that $\alpha_{t}$ varies over time when the reason that firms are sometimes reluctant to change their prices is that they fear negative customer reactions.

The production and aggregate demand structure of the model are based on Rotemberg and Woodford (1997). In particular, I suppose that each of a continuum of households produces his own differentiated good ${ }^{10}$ and that his utility function at $t$ is given by

$$
E_{0} \sum_{t=0}^{\infty} \beta^{t}\left[u\left(C_{t}^{i}\right)-v\left(y_{t}^{i}\right)\right]
$$

where $y_{t}^{i}$ is the output of household $i$ at $t$ while $C_{t}^{i}$ is the household's consumption at $t$. This

\footnotetext{
${ }^{9}$ In the absence of such steady state inflation, price decreases are sometimes optimal. The model is then only valid if any price change is acceptable only with probability $(1-\alpha)$. One way to justify the idea that price decreases could be seen as unfair is to lean on the assumption that consumers only re-evaluate the fairness of prices when these are changed. A price decrease then leads to such a re-evaluation and information about costs may then suggest that even a price lower than the one that prevailed previously is unfair.

${ }^{10}$ This captures in a simple way the market segmentation that is useful for ensuring that monetary policy has persistent effects (see Woodford (2003) for a discussion).
} 
consumption is, in turn, the aggregate of the consumption of many individual goods, with

$$
C_{t}^{i}=\left[\int_{0}^{1} c_{t}^{i}(z)^{\frac{\theta-1}{\theta}} d z\right]^{\frac{\theta}{\theta-1}}
$$

Supposing that there are full insurance markets and ignoring all other uses of output, each individual's consumption at $t$ is a fixed fraction of aggregate output $Y_{t}$. This means that quantity demanded of good $i$ is given by $Y_{t}\left(P_{t}^{i} / P_{t}\right)^{-\theta}$ where the $P_{t}^{i}$ is the price charged by household $i$ for its product and the price index $P_{t}$ is

$$
P_{t}=\left[\int_{0}^{1}\left(P_{t}^{i}\right)^{1-\theta} d i\right]^{\frac{1}{1-\theta}}
$$

In addition to having access to a full set of insurance markets, households can borrow and lend at the riskless nominal rate $R_{t}$. This means that they must be indifferent between consuming an additional unit of consumption at $t$ and expecting to consume $\left(1+R_{t}\right) P_{t} / P_{t+1}$ additional units of consumption at $t+1$. Thus

$$
E_{t}\left\{\frac{\beta\left(1+R_{t}\right) P_{t} u^{\prime}\left(C_{t+1}^{i}\right)}{P_{t+1}}\right\}=u^{\prime}\left(C_{t}^{i}\right) .
$$

Lastly, each producer can change his nominal price at time $t$ with probability $\alpha_{t}$. When changing prices at $t$, the producer maximizes lifetime utility knowing that a one dollar increase in profits in period $t+j$ raises expected utility at $t$ by $E_{t} \beta^{j} u^{\prime}\left(C_{t+j}^{i}\right) / P_{t+j}$. Thus, the optimal price maximizes

$$
E_{t} \sum_{j=0}^{\infty} \beta^{j}\left(\prod_{\ell=1}^{j} \alpha_{t+\ell}\right)\left[u^{\prime}\left(C_{t+j}^{i}\right) Y_{t+j}\left(\frac{P_{t}^{i}}{P_{t+j}}\right)^{1-\theta}-v\left(Y_{t+j}\left(\frac{P_{t}^{i}}{P_{t+j}}\right)^{-\theta}\right)\right]
$$

over $P_{t}^{i}$. The first order condition for this problem is

$$
E_{t} \sum_{j=0}^{\infty} \beta^{j}\left(\prod_{\ell=1}^{j} \alpha_{t+\ell}\right) Y_{t+j}\left(\frac{P_{t}^{i}}{P_{t+j}}\right)^{-\theta}\left[(1-\theta) u^{\prime}\left(C_{t+j}^{i}\right)\left(\frac{P_{t}^{i}}{P_{t+j}}\right)-\theta v^{\prime}\left(Y_{t+j}\left(\frac{P_{t}^{i}}{P_{t+j}}\right)^{-\theta}\right)\right]=0 .
$$

Dividing through by $\left(P_{t}^{i} / P_{t}\right)^{-\theta}$, the relative price of price changers $P_{t}^{i} / P_{t}$ satisfies

$$
X_{t}=\frac{\theta}{1-\theta} \frac{E_{t} \sum_{j=0}^{\infty} \beta^{j}\left(\prod_{\ell=1}^{j} \alpha_{t+\ell}\right) Y_{t+j}\left(\frac{P_{t}}{P_{t+j}}\right)^{-\theta} v^{\prime}\left(Y_{t+j}\left(\frac{P_{t}^{i}}{P_{t+j}}\right)^{-\theta}\right)}{E_{t} \sum_{j=0}^{\infty} \beta^{j}\left(\prod_{\ell=1}^{j} \alpha_{t+\ell}\right) Y_{t+j}\left(\frac{P_{t}}{P_{t+j}}\right)^{1-\theta} u^{\prime}\left(c_{t+j}^{i}\right)} .
$$


I consider the case where $u^{\prime}(c)$ equals $u_{o} c^{-\sigma}$ while $v^{\prime}(y)$ is proportional to $v_{o} y^{\omega}$. With complete markets and a unit mass of households, the consumption of each of them equals $Y_{t}$ at a symmetric equilibrium. Letting $X_{t}$ denote the relative price of price changers, it follows that

$$
X_{t}^{1+\theta \omega}=\frac{\theta v_{o} / u_{o}}{1-\theta} \frac{E_{t} \sum_{j=0}^{\infty} \beta^{j}\left(\prod_{\ell=1}^{j} \alpha_{t+\ell}\left(1+\pi_{t+\ell}\right)^{\theta(1+\omega)}\right) Y_{t+j}^{1+\omega}}{E_{t} \sum_{j=0}^{\infty} \beta^{j}\left(\prod_{\ell=1}^{j} \alpha_{t+\ell}\left(1+\pi_{t+\ell}\right)^{\theta-1}\right) Y_{t+j}^{1-\sigma}}
$$

where $\pi_{t}=\frac{P_{t}-P_{t-1}}{P_{t-1}}$ The absence of taste changes implies that output is a constant $Y$ at a deterministic steady state with constant inflation $\pi$. At such a steady state, the relative price of price changers is

$$
X=Y^{\omega+\sigma} \frac{1-\alpha \beta(1+\pi)^{\theta-1}}{1-\alpha \beta(1+\pi)^{\theta(1+\omega)}}
$$

where $\alpha$ is the steady state probability of changing prices.

There is also an additional relation between $X$ and $\pi$ that follows mechanically from the definition (13) and the fact that all price changers set the same price. Using (13), the common choice of $P_{t}^{i} / P_{t}$ implies

$$
\left[\left(1-\alpha_{t}\right) X_{t}^{1-\theta}+\alpha_{t}\left(\frac{P_{t-1}}{P_{t}}\right)^{1-\theta}\right]^{\frac{1}{1-\theta}}=1
$$

In steady state, this implies

$$
(1-\alpha) X^{1-\theta}+\alpha(1+\pi)^{\theta-1}=1
$$

Together with (17) this can be solved for the values of $X$ and $Y$ that hold at a deterministic steady state with constant $\pi$. At such a steady state, the relative price of each price setter declines until he is again able to set his relative price to $X$. I approximate the equilibrium near such a steady state and let $\tilde{x}_{t}, \tilde{y}_{t}, \tilde{\alpha}_{t}$ and $\tilde{\pi}_{t}$ denote the logarithmic deviations from their steady state values of of $X, Y, \alpha$ and $1+\pi$ respectively.

Differentiating (18), and using (19) to substitute for the steady state value of $X$, one obtains

$$
\tilde{\pi}_{t}=\frac{1-\alpha(1+\pi)^{\theta-1}}{\alpha(1+\pi)^{\theta-1}} \tilde{x}_{t}+\frac{(1+\pi)^{1-\theta}-1}{(1-\alpha)(\theta-1)} \tilde{\alpha}_{t}
$$


Differentiating (16),

$$
(1+\theta \omega) \tilde{x}_{t}=E_{t} \frac{1}{1-\lambda_{1} / L}\left(c_{1}^{y} \tilde{y}_{t}+\lambda_{1} \tilde{\alpha}_{t+1}+\lambda_{1} \theta(1+\omega) \tilde{\pi}_{t+1}\right)+E_{t} \frac{1}{1-\lambda_{2} / L}\left(c_{2}^{y} \tilde{y}_{t}-\lambda_{2} \tilde{\alpha}_{t+1}-\lambda_{2}(\theta-1) \tilde{\pi}_{t+1}\right)
$$

where $L$ is the lag operator and the parameters $c_{1}^{y}, c_{2}^{y}, \lambda_{1}$ and $\lambda_{2}$ are given by

$$
\begin{array}{ll}
\lambda_{1} \equiv \alpha \beta(1+\pi)^{\theta(1+\omega)} & \lambda_{2} \equiv \alpha \beta(1+\pi)^{\theta-1} \\
c_{1}^{y} \equiv(1+\omega)\left(1-\lambda_{1}\right) & c_{2}^{y} \equiv(\sigma-1)\left(1-\lambda_{2}\right) .
\end{array}
$$

When the steady state rate of inflation $\pi$ equals zero, the coefficient of $\tilde{\alpha}$ in (20) equals zero. In addition, $\lambda_{1}=\lambda_{2}=\alpha \beta$ in this case, so that the coefficient of $\tilde{\alpha}$ in (21) is zero as well. Thus small variations in $\alpha$ have no effect on economic outcomes. The reason is that, with zero steady state inflation, the steady state value of $X$ is 1.00 so that the typical price changer changes his price by zero percent. Thus, an increase in the number of price changers does not typically affect the price level. When inflation is positive, by contrast, $X>1$ and the typical price changer raises his price. While the effect of changes in $\alpha$ is necessarily small for $\pi$ sufficiently small, I show below that the effect of small variations in $\tilde{\alpha}$ can be significant if steady state inflation is equal to just 5 percent per year.

To compute these effects, it is worth multiplying both sides of $(21)$ by $\left(1-\lambda_{1} / L\right)\left(1-\lambda_{2} / L\right)$ to obtain

$$
\begin{gathered}
E_{t}\left[\tilde{x}_{t}-\left(\lambda_{1}+\lambda_{2}\right) \tilde{x}_{t+1}+\lambda_{1} \lambda_{2} \tilde{x}_{t+2}\right]=E_{t}\left[\left(c_{1}^{y}+c_{2}^{y}\right) \tilde{y}_{t}-\left(c_{1}^{y} \lambda_{2}+c_{2}^{y} \lambda_{1}\right) \tilde{y}_{t+1}+\left(\lambda_{1}-\lambda_{2}\right) \tilde{\alpha}_{t+1}\right. \\
\left.+\left((1+\theta \omega) \lambda_{1}+\left(\lambda_{2}-\lambda_{1}\right)(1-\theta)\right) \tilde{\pi}_{t+1}-\lambda_{1} \lambda_{2}(1+\theta \omega) \tilde{\pi}_{t+2}\right]
\end{gathered}
$$

The computation of deviations from the steady state equilibrium require also the linearization of (14), which is given by

$$
E_{t}\left[\sigma\left(\tilde{y}_{t+1}-\tilde{y}_{t}\right)-\tilde{i}_{t}+\tilde{\pi}_{t+1}\right]=0
$$

where $\tilde{i}_{t}$ is the log deviation of the total nominal return from its steady state value. The computation of responses to monetary policy also requires a specification of the systematic 
component of this policy. For purposes of illustration, I suppose that the reaction function of the central bank is given by

$$
\tilde{i}_{t}=c_{\pi}^{i} \tilde{\pi}_{t}+c_{1}^{i} \tilde{i}_{t-1}+\epsilon_{t}^{i}
$$

The object of the next section is to analyze the response of the economy to monetary policy shocks $\epsilon_{t}^{i}$. The main contribution of this analysis relative to the existing literature is that I seek to incorporate the idea that customers resistance to price changes evolves over time. This evolution obviously affects the extent to which firms change prices so that it affects $\alpha_{t}$. Before discussing these changes, I start with the standard specification where $\alpha$ is constant. While the exercise I carry out is only meant to be illustrative, I use parameter values that are similar to those in the literature. I suppose, in particular that $\beta=.99$, $\sigma=1$ while I set $\theta$ and $\omega$ a the values of Rotemberg and Woodford (1997) of 7.88 and .47 respectively. I consider separately the case where annual inflation equals $5 \%$ and the one where it equals $50 \%$.

As when there are fixed costs of changing prices, one would expect price adjustment to be more frequent when inflation is more rapid. On the other hand, fixed costs of changing prices also imply that the departure of the reset price from the average price (i.e. $X$ ) is larger when inflation is larger, and this is consistent with the experience of high inflation countries. I thus suppose that, when annual inflation equals 5\%, the typical price-changing firm sets a price $5 \%$ above that of its peers so that the steady state value of $X$ equals 1.05 . The typical price changer is then raising his price by $P_{t}^{i} / P_{t-1}$, or $X(1+\pi)$, which equals $6.3 \%$. Using (19), this value of $X$ implies that firms adjust their prices on average once a year and $\alpha$ equals .76. By contrast, when I let annual inflation equal $50 \%$, I suppose $X=1.06$ and the resulting value of $\alpha$ is only .25. Aside from the consistency with models of fixed costs of changing prices, Bakhshi et al (2002) report that having $\alpha$ fall relatively rapidly with inflation is necessary to ensure that output does not become excessively sensitive to inflation as steady state inflation rises.

I let the two parameters of the monetary policy rule, $c_{\pi}^{i}$ and $c_{1}^{i}$ equal .9. I choose these 
high values both to ensure that the $\epsilon_{t}^{i}$ shock has persistent effects and to obtain a determinate equilibrium. It turns out that the conditions for determinacy are substantially more stringent when the equilibrium is approximated around a steady state with positive inflation then when it is approximated around one with zero inflation, as is more standard. In the standard case, discussed for example in Woodford (2003), determinacy obtains even with $c_{1}^{i}=0$ as long as $c_{\pi}^{i} \geq 1$. By contrast,if $c_{1}^{i}=0$ determinacy in the case of the parameters I use when $\pi=.05$ requires that $c_{\pi}^{i}$ be no smaller than $2.8 .^{11}$

\section{Monetary Policy}

For the case of constant $\alpha$, the effects of a unit increase in $\epsilon_{t}^{i}$ when the annual rate of inflation is either 5 or $50 \%$ (which correspond to quarterly rates $\pi$ of .012 and .107 respectively) are depicted in Figure 2. When $\pi=.012$, the effect on output is large relative to the effect on inflation. The reason for this is that $c_{1}^{i}$ is large (see Woodford (2003) for a discussion of the effects of this parameter). By contrast, the effects on inflation are larger and the effects on output are smaller when $\pi=.107$. In this case, the low value of $\alpha$ leads prices to respond more quickly. Given (23), this also implies that the interest rate returns more quickly to its steady state value.

One standard result in this figure is that, for either steady state inflation rate, the drop in inflation is largest in the first quarter and then tapers off relatively quickly. Since the drop in demand is largest at $t$ firms adjusting at $t$ set a lower value of $X$ than firms adjusting later. This pattern of responses of inflation to monetary policy shocks differs from estimated responses because, in the latter, the largest reduction in inflation takes place sometime after the monetary policy shock. Rotemberg and Woodford (1997) find that the biggest response takes place after two quarters and show that a model with delays in price setting can account for these delays. Other studies find longer delays, with Christiano, Eichenbaum and Evans

\footnotetext{
${ }^{11}$ This substantial quantitative difference in the case of the two approximations fits well with the results of Ascari (2000) and Bakhshi et al (2002), who also show that this model behaves differently with even modest levels of steady state inflation. The differences reported by Bakhshi et al (2002) can be offset by changes in $\alpha$, however, whereas determinacy in the approximation with zero steady state inflation is independent of $\alpha$.
} 
(2001) reporting a maximum response after 9 quarters. ${ }^{12}$

In an important extension of the Calvo (1983) model, Dotsey, King and Wollman (1999) maintain the assumption that costs of changing prices are independently distributed over time for each individual firm but relax the assumption that these costs are drawn from a two point distribution where the costs are either negligible or prohibitive. Instead, they let the costs be drawn from a compact set. When a firm faces the lowest possible cost of changing prices, it is quite likely to adjust its price. It is less likely to do so if this realized cost is somewhat higher because it is then tempting to wait in the hope that future costs will be lower. On the other hand, a firm will change its price even if its realized cost is relatively high as long as its existing price is sufficiently far from the optimal one because it has recently drawn a series of large costs of changing prices. While their model incorporates variations in the costs of changing prices for individual firms, they suppose that the costs of changing prices for the "typical" firm do not vary over time.

Unfortunately, this modification appears to exacerbate the tendency for inflation to fall immediately when interest rates are increased. ${ }^{13}$ The reason is that, in an environment with positive steady state inflation, a reduction in future inflation means that the prices that maximize profits in the future are now closer to $P_{t}$ itself. This is reflected in the fall in $X_{t}$ at the moment that $\epsilon_{t}^{i}$ rises. The fact that an increase in $\epsilon_{t}^{i}$ leads firms that change prices to raise them by less implies that it also lowers the payoff from adjusting prices relative to the payoff of doing nothing. With a compact set of realizations for the cost of changing prices, this reduces the fraction of firms that adjust their prices at $t$. Since the typical priceadjusting firm is actually increasing its price, this reduction in the fraction of firms that adjust their price lowers inflation at $t$ even further.

If, instead, price rigidity is due to fear of customer reactions rather than to fixed costs of changing prices, one would expect a rather different pattern of responses. In particular, one

\footnotetext{
${ }^{12}$ They also argue that introducing an empirically plausible delay between the time that inputs must be acquired and the time that output is sold can account for this delay.

${ }^{13}$ They carry out their analysis by considering changes in the growth of the money supply. However, the logic of their analysis ought to carry over to monetary policy reaction functions like (23).
} 
would expect that the reduction in $X_{t}$ induced by a contractionary monetary policy would make it easier for firms to raise their prices so that they charge their desired price. Thus, if consumers react to the the price charged by price changers, more firms might be willing to change their price after a monetary contraction.

A formal model where this occurs is the following. Suppose that firms draw a "type" each period and let $z$ index the type with $H(z)$ representing the density of $z$. Firms with a higher $z$ can get away with charging a higher relative price $X$, and the maximum allowable $X$ is a function $g(z)$. There is a particular value of $z, \bar{z}$ such that firms with a $z \geq \bar{z}$ can charge any price that they desire without incurring negative reactions and I suppose that $H(\bar{z})<1$. Lastly, I suppose that consumers observe the price charged by the firms who can charge any price they want and react negatively with respect to any firm that changes its price but charges a price different from the one charged by these firms.

This can be justified as follows. Consumers would have good reason to be angry with firms that charge more than those who are able to charge any price they wish. However, given that all firms are symmetric in my model, no firm would wish to do so. The question is then why consumers would react negatively to price-changing firms whose price relative to $P_{t}$, is lower than that charged by the firms who are free to choose their price. One justification for this is that, by charging a lower price, these firms draw attention to the fact that consumers would react with anger if they charged the same price as that charged by the unconstrained price changers. When consumers realize that these firms are not entitled to charge the same price as these other price changers, they react with suspicion to any price change at all.

It follows form this set of assumptions that the firms with $z \geq \bar{z}$ charge the price that maximizes (15), $P_{t} X_{t}$. Firms whose $z$ is above $g^{-1}\left(X_{t}\right)$ do the same. However, those whose $z$ is below $g^{-1}\left(X_{t}\right)$ keep their price constant. They can neither charge $P_{t} X_{t}$ nor a lower price that differs from their past price. Thus, $\alpha_{t}=H\left(g^{-1}\left(X_{t}\right)\right)$. Linearizing this,

$$
\tilde{\alpha}_{t}=c_{X}^{\alpha} \tilde{x}_{t}
$$

where the parameter $c_{X}^{\alpha}$ is positive. Figure 3 reports responses for the case where (24) holds 
with $c_{X}^{\alpha}$ equal to 2.5 and $\pi=.012$. For comparison, it also reports that responses when $\alpha_{t}$ is constant. Having $\alpha_{t}$ fall with $X_{t}$ implies that inflation falls less on impact because more firms change their prices and the typical price changer increases its price. Given the monetary policy rule (23), this reduced fall in inflation implies that interest rates do not fall back as rapidly towards their steady state values. This latter effect is so quantitatively important that real interest rates rise by more and drop more slowly in the case of variable $\alpha$. This explains why output falls by more in this case.

One disappointing feature of the Figure 3 is that inflation still falls by the largest amount on impact. This ceases to be true, however, once one adds one more determinant to $\alpha$. As discussed above, consumers are likely to use estimates of cost increases to decide whether price rises are justified. If recent inflation has been relatively low, they are likely to believe that cost increases have been modest and are likely to be less tolerant of price increases. One can model this by supposing that $z$ is once again the i.i.d. "type" drawn by each firm but that the maximum relative price a firm can charge is $X=g\left(z, \tilde{\pi}_{t-1}\right)$. A higher $\pi_{t-1}$ increases the $X$ that a firm can charge, or reduces the $z$ that is needed for any particular $X$. I continue to suppose that there is a strictly positive mass of firms that can charge any price they wish and that no price changer can charge a price that differs from that charged by these privileged firms. The fraction of privileged firms presumably varies with $\pi_{t-1}$ as well, but that is not important for my analysis.

Let $z=\hat{g}^{-1}\left(X, \pi_{t-1}\right)$ be the type of a firm that can raise its price to $X$ if past inflation were equal to $\pi_{t-1}$. Obviously, $z$ is lower for a given $X$ if $\pi_{t-1}$ is larger. The fraction of firms that keeps its prices constant, $\alpha_{t}$, is then given by $H\left(\hat{g}^{-1}\left(X_{t}, \pi_{t-1}\right)\right)$. Linearizing, this yields

$$
\tilde{\alpha}_{t}=c_{X}^{\alpha} \tilde{x}_{t}+c_{\pi}^{\alpha} \tilde{\pi}_{t-1}
$$

where $c_{\pi}^{\alpha}$ is negative.

Figures 4 and 5 report responses when $\tilde{\alpha}$ is given by (25). The parameter $c_{X}^{\alpha}$ is set equal to 2.5 in both cases while $c_{\pi}^{\alpha}=-15$ when $\pi=.012$ and $c_{\pi}^{\alpha}=-10$ when $\pi=.107$. These parameters are such that $\alpha_{t}$ initially falls (because $X_{t}$ falls) and then rises (because inflation 
falls). The result is that, when the annual steady state inflation rate is $5 \%$, inflation has its lowest point two quarters after the monetary shock. Moreover, the fall in inflation is much smaller in the initial quarter than when $\alpha$ is fixed. In the latter case, inflation falls by about $.18 \%$ with an initial increase in the rate of interest of $.88 \%$. By contrast, when $\alpha$ is given by (25), inflation falls initially by only .06\% even though the interest rate rises by $.95 \%$. This difference obtains even though the fraction of firms keeping their price constant falls by only about $1.8 \%$. Since firms who adjust their price in steady state do so by about $6.3 \%$, having $1.8 \%$ more of them do so raises inflation by about .11\% so this does not fully account for the difference in inflation responses. The rest is accounted for by the fact that $X_{t}$ falls more when $\alpha$ is constant. This occurs because, with variable $\alpha$, firms who adjust their price realize that price adjustments will become more infrequent in the future (because the reduction in inflation will push up $\left.\alpha_{t+j}\right)$. Given the existence of underlying inflation, this leads them to charge slightly higher prices at $t$.

Interestingly, neither the path of output nor that of interest rates is significantly affected by these changed dynamics of inflation. The lack of monotonicity in the inflation response means that the real rate rises less initially but stays higher for a longer period of time when $\alpha$ is variable. The real rate of interest on a long term bond, which determines the initial response of output, is similar in both cases.

In the case of Figure 5, where the annual steady state inflation rate is $50 \%$, the effect of using (25) on the output and interest rate responses is larger. Inflation is much lower on impact than with a fixed $\alpha$ and it reaches its lowest point in the second quarter rather than the first. The reason the decline in inflation is so much smaller even though $\alpha_{t}$ falls by less than one percent is that the typical price changer is now changing prices by $17.3 \%$ so that having $1 \%$ more price changers raises inflation by $.17 \%$. By the same token, the higher underlying inflation means that the expectation of an increase in the future value of $\alpha$ has a substantial effect on $X_{t}$. Because inflation falls so much less, interest rates are not brought back as quickly with variable $\alpha$ and output falls much more.

This quantitative analysis suggests that, as could be expected from the analytical dis- 
cussion, the effect of variable $\alpha$ is a great deal more important in countries whose average inflation is higher. Indeed, it suggests that fairly large recessions can still be induced in such settings by tightening monetary policy. This result is attractive because, when inflation is high, the frequency of price adjustment is high as well so it would seem that a model with fixed frequency of price adjustment has almost no chance to produce output reductions in response to highly visible changes in monetary policy. Yet, stabilizations in high inflation countries often do involve substantial losses in output.

I have given a particular model of consumer reactions where $\alpha_{t}$ respond endogenously by first falling and then rising in response to a monetary tightening. In part because the responses of $\alpha$ are not derived from a detailed model of consumer behavior and in part because there are other reasons for $\alpha$ to respond in this way, I now carry out some calculations treating $\alpha$ as exogenous. In other words, I look at the impulse responses of output, inflation and interest rates to monetary shocks by considering what seem a priori plausible responses of $\alpha_{t}$. One purpose of this exercise is to show that, in principe, such variations in $\alpha$ ought to make it considerable easier to explain actual responses to monetary policy. The flip side of this is that variations in $\alpha_{t}$ ought in principle to be observable. Thus, a more ambitious research agenda would analyze how the rest of the economy ought to react given the actual responses of the fraction of firms changing prices. It would then proceed also to try to explain the actual movement in the fraction of price changers.

Before carrying out this analysis, it is worth giving one additional reason for $\alpha$ to fall in the immediate aftermath of a monetary contraction. Such a contraction ought to lead sophisticated price setters to realize that inflation will slow so that price increases will become more difficult to "sell" in the future. This leads to the conjecture that some price setters that would have kept their prices constant in the absence of the tightening ought to raise prices and thereby increase the risk of contemporaneous negative reactions by customers. The advantage of doing so is that price setters can still point to past inflation as a reason for the price increase while this will become harder in the future. Unfortunately, this mechanism does not fit into the model I developed so far because, for simplicity, I looked at a 
setting where firms keep the probability of negative reactions equal to zero. By contrast, the mechanism I just suggested requires that firms be willing to increase this probability above zero under some circumstances.

The pattern of exogenous responses of $\alpha_{t}$ that I consider is depicted in Figure 6. For the simulations, I use a difference equation to describe this response, and this difference equation is

$$
\tilde{\alpha}_{t}=1.02 \tilde{\alpha}_{t-1}-.116 \tilde{\alpha}_{t-2}-.302 \tilde{\alpha}_{t-3}-c^{\epsilon} \epsilon_{t}^{i}
$$

where the parameter $c^{\epsilon}$ varies with the specification. According to this equation, a monetary contraction first raises the fraction of price adjusters and, after a few quarters, lowers this fraction below its steady state value. This pattern would be reasonable if inflation stayed near the steady state for several quarters and then dipped below, because this would justify both the initial rush of price adjustments and the subsequent reduction in the fraction of adjusters. The initial rush could then be due either to the reduction in $X_{t}$ or to the desire to raise prices while one can still point to a recent episode of relatively high inflation.

With $c^{\epsilon}$ set equal to 3 , the resulting responses of output, inflation and interest rates are plotted in Figure 6 as well. The Figure shows that the response of inflation is indeed delayed for several quarters, and inflation reaches its minimum 6 quarters after the initial burst of interest rates. Thus, the pattern of responses in $\alpha$ that I have assumed seems to yield the pattern of inflation responses (where inflation at first does little even though $X$ falls and then inflation later declines) which makes the assumed response of $\alpha$ reasonable. It is worth noting, however, that my assumed responses of $\alpha$ are substantially larger in absolute magnitude than the responses of inflation. It remains unclear whether such a difference in the size of these responses is justifiable through an explicit model of consumer behavior.

Because inflation responds so modestly, (23) implies that interest rates do not return quickly to their steady state value. This means that real interest rates stay high for some time and that the output drop is considerable. Such large output declines are not particularly realistic but the main point of the exercise is to show that contractionary monetary policy with long lived output effects is perfectly consistent with muted and delayed responses of 
inflation.

One obviously unrealistic feature of the responses that I have displayed so far is that output has its biggest fall instantaneously. To describe situations where output falls only over time the model has to be modified either by adding decision lags (as in Rotemberg and Woodford 1997) or by changing the specification of preferences so consumers try to smooth output changes. As suggested by Fuhrer (2000), one way of obtaining "hump shaped" responses of output in monetary models of this type is to suppose that consumers have preferences that can be characterized by "habit persistence". I now consider briefly a modification of the model along these lines.

I let $\bar{C}_{t}$ represent the "habit" and specialize the utility from consumption so it is given by

$$
E_{0} \sum_{t=0}^{\infty} \beta^{t}\left[\frac{\left(C_{t}^{i}\right)^{1-\sigma}}{(1-\sigma) \bar{C}_{t}}-v\left(y_{t}^{i}\right)\right]
$$

I follow Abel (1990) and let this habit be external to the individual. Specifically, I suppose that $\bar{C}_{t}=Y_{t-1}^{\psi}$. The case $\psi=0$ corresponds to the utility function I have used so far.

The consumer must still be indifferent to consuming one less dollar at $t$ and consuming the proceeds from investing this dollar in a nominal asset yielding $R_{t}$ at $t+1$. This now requires that

$$
E_{t} \beta \frac{\left(1+R_{t}\right) P_{t} Y_{t-1}^{\psi} C_{t+1}^{-\sigma}}{P_{t+1} Y_{t}^{\psi} C_{t}^{-\sigma}}=1
$$

Linearizing this equation around a steady state while remembering that $C_{t}=Y_{t}$ yields

$$
E_{t}\left[\sigma\left(\left(\tilde{y}_{t+1}-\bar{\psi} \tilde{y}_{t}\right)-\left(\tilde{y}_{t}-\bar{\psi} \tilde{y}_{t-1}\right)\right)-\tilde{i}_{t}+\tilde{\pi}_{t+1}\right]=0
$$

where $\bar{\psi}=-\psi / \sigma$.

This change in the utility function also affects the value of marginal utility in (15). Using $Y_{t}^{-\sigma} / Y_{t-1}^{\psi}$ for this marginal utility, (16) becomes

$$
X_{t}^{1+\theta \omega}=\frac{\theta v_{o} / u_{o}}{1-\theta} \frac{E_{t} \sum_{j=0}^{\infty} \beta^{j}\left(\prod_{\ell=1}^{j} \alpha_{t+\ell}\left(1+\pi_{t+\ell}\right)^{\theta(1+\omega)}\right) Y_{t+j}^{1+\omega}}{E_{t} \sum_{j=0}^{\infty} \beta^{j}\left(\prod_{\ell=1}^{j} \alpha_{t+\ell}\left(1+\pi_{t+\ell}\right)^{\theta-1}\right) Y_{t+j}^{1-\sigma} Y_{t+j-1}^{-\psi}}
$$

To compute impulse responses, the linearized equations (21) and (22) must be modified accordingly. I compute these responses for $\bar{\psi}=.7$ and plot them in Figure 7 , which also 
shows the responses for constant $\alpha_{t}$ as a benchmark. When comparing Figures 6 and 7 for the case of constant $\alpha$, one sees that the higher value of $\psi$ does induce a hum-shaped response of output. In addition, the effect of the monetary disturbance on inflation rises, particularly relative to the response of output. With $c^{\epsilon}=3$, on the other hand, the response of output to the monetary disturbance is quite large, though it remains hump-shaped. The reason, in part, is that the resulting swings in $\alpha$ are large enough to mute considerably the initial response of inflation. This means that the real interest rate rises a great deal and this induces large swings in output.

Figure 7 thus shows that hump shaped responses of output together with modest inflation responses are not at all inconsistent with the model as long as $\alpha$ varies in the requisite ways. The qualitative features of the required response of $\alpha$ remain intuitively appealing. Whether the actual magnitude of this response is either empirically valid and whether it can be derived from a quantitative model of consumer behavior remain open questions for research.

\section{Conclusions}

This paper has shown that the threat of consumer anger can account for the constancy of prices from one period to the next while also having the potential for explaining some of the dynamic responses of the economy to monetary policy shocks. The consumer reactions I have focused on are "irrational" in the sense that consumers are maximizing something other than a utility function that depends only on their own material payoffs. Rather, they also wish to harm (or at least not to help) firms that they see as having given them a bad deal. Understandably, this leads firms to be careful not to induce these emotional reactions.

One attraction of modelling price rigidity as stemming from consumer reactions is that this provides a new mechanism through which lack of information about economic conditions translates into muted price responses. It is easy to believe that consumers are poorly informed about cost changes and this may lead firms that are concerned about consumer reactions to make their prices less sensitive to costs. By contrast, more standard models in which poor information leads to sluggish price adjustment suppose directly that producers are 
imperfectly informed about either costs or demand. Given the huge incentives for producers to acquire all relevant information and given that a small number of sophisticated individuals makes the bulk of the economy's pricing decisions, this approach seems less attractive.

Having said this, the model I have constructed has not explored deeply how consumers update their information about producer fairness, and this deserves further investigation. One reason this is particularly important is that, while producers can be expected to have good information about their own cost conditions, they are likely to know less about what consumers regard as fair. In particular, they are likely to know less about the information that consumers have about the producers' costs. This departure from full information may well prove important in elaborations of the model I have presented here.

Heterogeneity in information sets ought not to be confined to differences between producers and consumers. Consumers, in particular, are likely to differ a great deal from each other in both their information and their attitude towards suppliers. Nonetheless, anger at producers appears to be communicable and this seems capable of leading to the sort of discontinuous change in purchases that I have modelled in this paper. Thus, information transmission from one set of consumers to another, particularly in situations where some consumers feel that the firm has stepped over the line, seems to be important in practice. Modelling this information transmission thus remains an important topic for future research.

\section{References}

Abel, Andrew B., "Asset Prices under Habit Formation and Catching up with the Joneses," American Economic Review,, 80, May 1990, 38-42.

Ascari, G. "Staggered Price and Trend Inflation: Some Nuisances," mimeo, 2000.

Bakhshi, Hasan, Pablo Burriel-Llombart, Hashmat Khan and Barbara Rudolf, "Endogenous Price Stickiness, trend Inflation and the New Keynesian Phillips Curve," mimeo 2002.

Blinder, Alan S., Elie R.D. Canetti, David E. Lebow and Jeremy B. Rudd, Asking about Prices: A New Approach to Understanding Price Stickiness, New York: Russell 
Sage, 1998.

Barsky, Robert, Mark Bergen, Shantanu Dutta and Daniel Levy, "What Can the Price Gap Between Branded and Private Label Products Tell Us About Markups?" in Robert Feenstra and Matthew Shapiro, editors, Scanner Data and Price Indexes, Studies in Income and Wealth No. 64 University of Chicago Press, 2002.

Calvo, Guillermo, "Staggered Prices in a Utility-Maximizing Framework," Journal of Monetary Economics, 12(3), 1983, 383-98.

Campbell, Margaret C., "Perceptions of price Unfairness: Antecedents and Consequences," Journal of Marketing Research,, 36, May 1999, 187-99.

Christiano, Lawrence J., Martin Eichenbaum and Charles Evans, "Nominal Rigidities and the Dynamic Effects of a Shock to Monetary Policy," NBER Working Paper 8403, July 2001.

Dolan, Robert J. and Hermann Simon, Power Pricing, New York: The Free Press, 1996.

Dotsey, Michael, Robert G. King and Alexander Wolman, "State-Dependent Pricing and the General Equilibrium Dynamics of Money and Output," Quarterly Journal of Economics, 114, May 1999, 655-90.

Dufwenberg, Martin and Georg Kirchsteiger, "A Theory of Sequential Reciprocity," mimeo, 2001.

Falk, Armin and Urs Fiscbacher, "A Theory of Reciprocity," Institute for Empirical Economics, University of Zurich, Working Paper, July 2000.

Fuhrer, Jeffrey C., "Habit Formation in Consumption and its Implications for MonetaryPolicy Models," American Economic Review,, 90, June 2000, 367-90.

Kahneman, Daniel, Jack Knetsch and Richard Thaler, "Fairness as a Constraint on Profit: Seeking Entitlements in the Market," American Economic Review, 76, September 1986, 728-41.

Hall, R. L. and C. J. Hitch, "Price Theory and Business Behaviour," Oxford Economic Papers, May 1939, 12-45.

Hendel, Igal and Aviv Nevo, "Sales and Consumer Behavior," NBER Working Paper 9048, July 2002.

Levy, Daniel, Mark Bergen, Shantanu Dutta and Robert Venable, "The Magnitude of Menu Costs: Direct Evidence from Large U.S. Supermarket Chains," Quarterly 
Journal of Economics, 112, August 1997, 791-825.

Lucas, Robert E. Jr. "Expectations and the Neutrality of Money," Journal of Economic Theory, 4, 1972, 103-124.

Mankiw, N. Gregory and Ricardo Reis, "Sticky Information versus Sticky Prices: A Proposal to Replace the New Keynesian Phillips Curve," NBER Working Paper 8290, May 2001.

Miller, Jack E. Menu Pricing, Boston: Cahners, 1976.

Oxenfeldt, Alfred R., Industrial Pricing and Market Practices,, New York: Prentice Hall, 1951.

Rabin, Matthew, "Incorporating Fairness into Game Theory and Economics," American Economic Review, 83, December 1993, 1281-1302.

Rotemberg, Julio J., "Monopolistic Price Adjustment and Aggregate Output," Review of Economic Studies, 49, October 1982, 517-31.

- "Altruism, Reciprocity and Cooperation in the Workplace," forthcoming in GerardVaret, Louis-André, Serge-Christophe Kolm and Jean Mercier Ythier, Handbook on the Economics of Giving, Reciprocity and Altruism, North Holland, 2003.

Rotemberg, Julio J., and Michael Woodford, "An Optimization-Based Econometric Framework for the Evaluation of Monetary Policy," NBER Macroeconomics Annual 1997, $297-346$.

Sheshinski, Eytan and Yoram Weiss, "Inflation and Costs of Price Adjustment," Review of Economic Studies, 44, 1977, 287-303.

Stiglitz, Joseph E., "Price Rigidities and Market Structure," American Economic Review, 74, May 1984, 350-5.

Woodford, Michael, "Imperfect Common Knowledge and the Effects of Monetary Policy," mimeo 2002.

—, Interest and Prices, Princeton, Princeton University Press, 2003.

Zbaracki, Mark J., Mark Riston, Daniel Levy, Shantanu Dutta and Mark Bergen, "Managerial and Customer Costs of Price Adjustment: Direct Evidence from Industrial Markets," mimeo 2002. 
Figure 1: Pricing at Dominick's

\section{Nabisco Premium Saltines 16oz.}

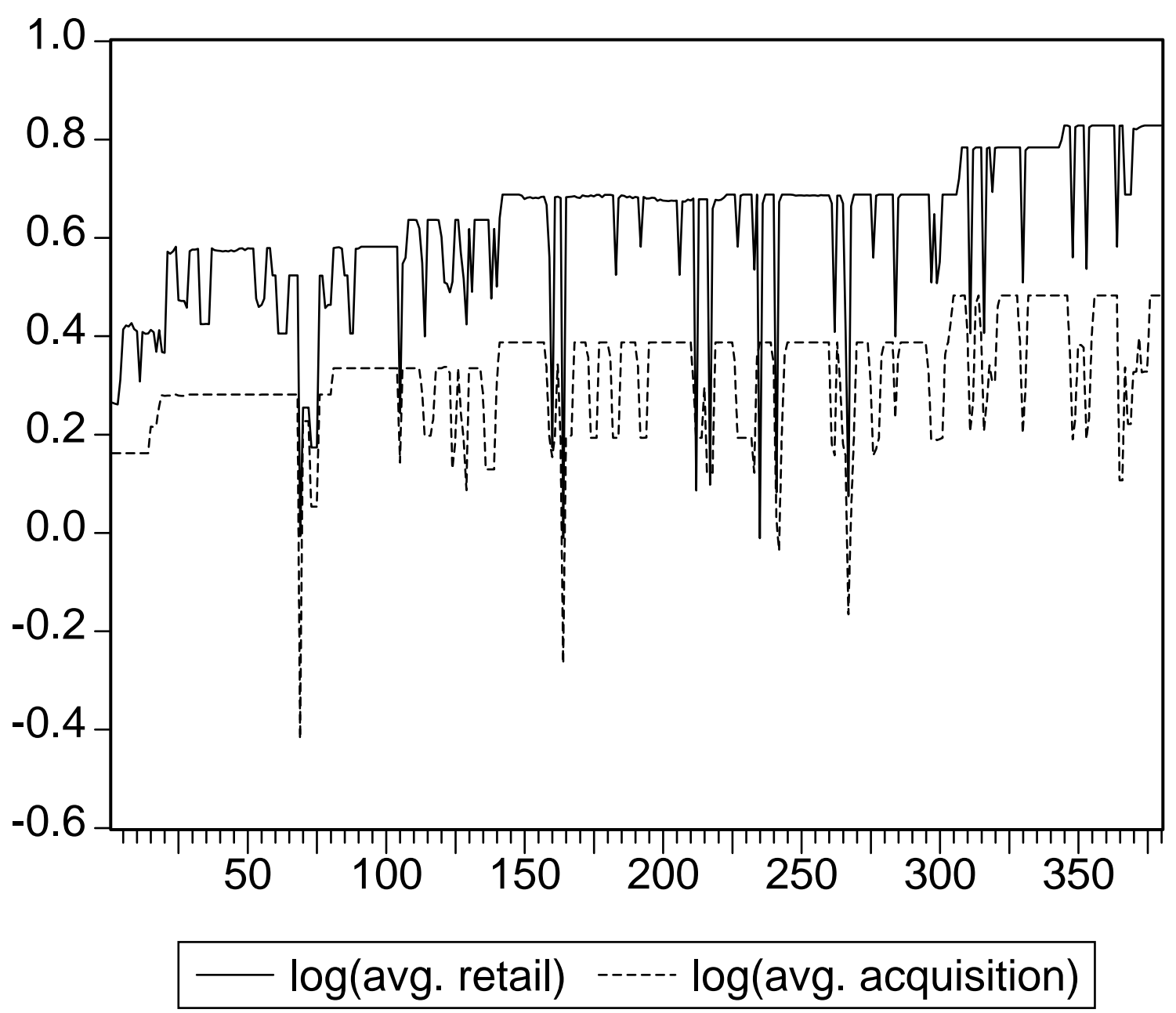


Figure 2: Responses with constant $\alpha$
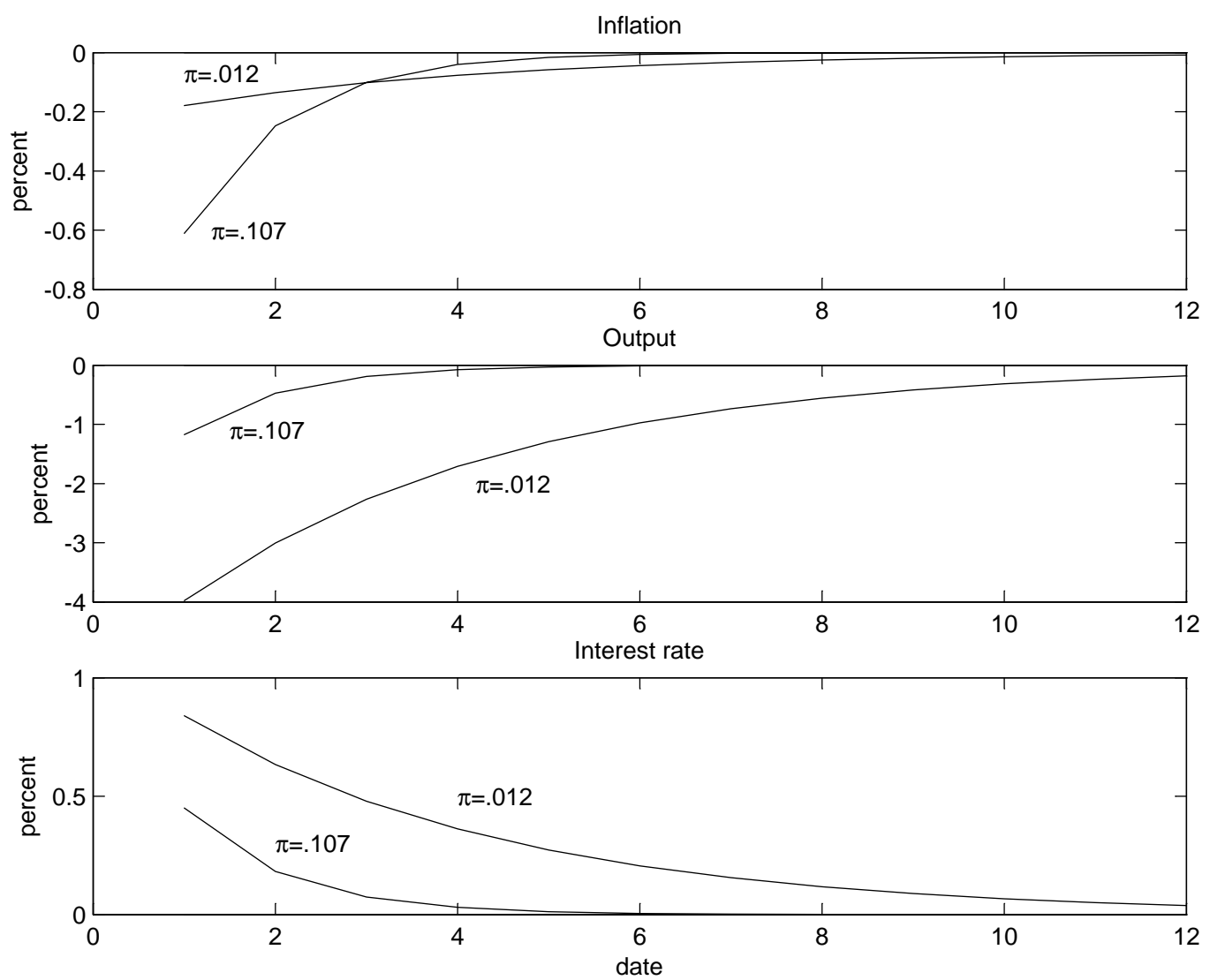
Figure 3: Responses when $\tilde{\alpha}$ responds to $\tilde{x}, \pi=.012$
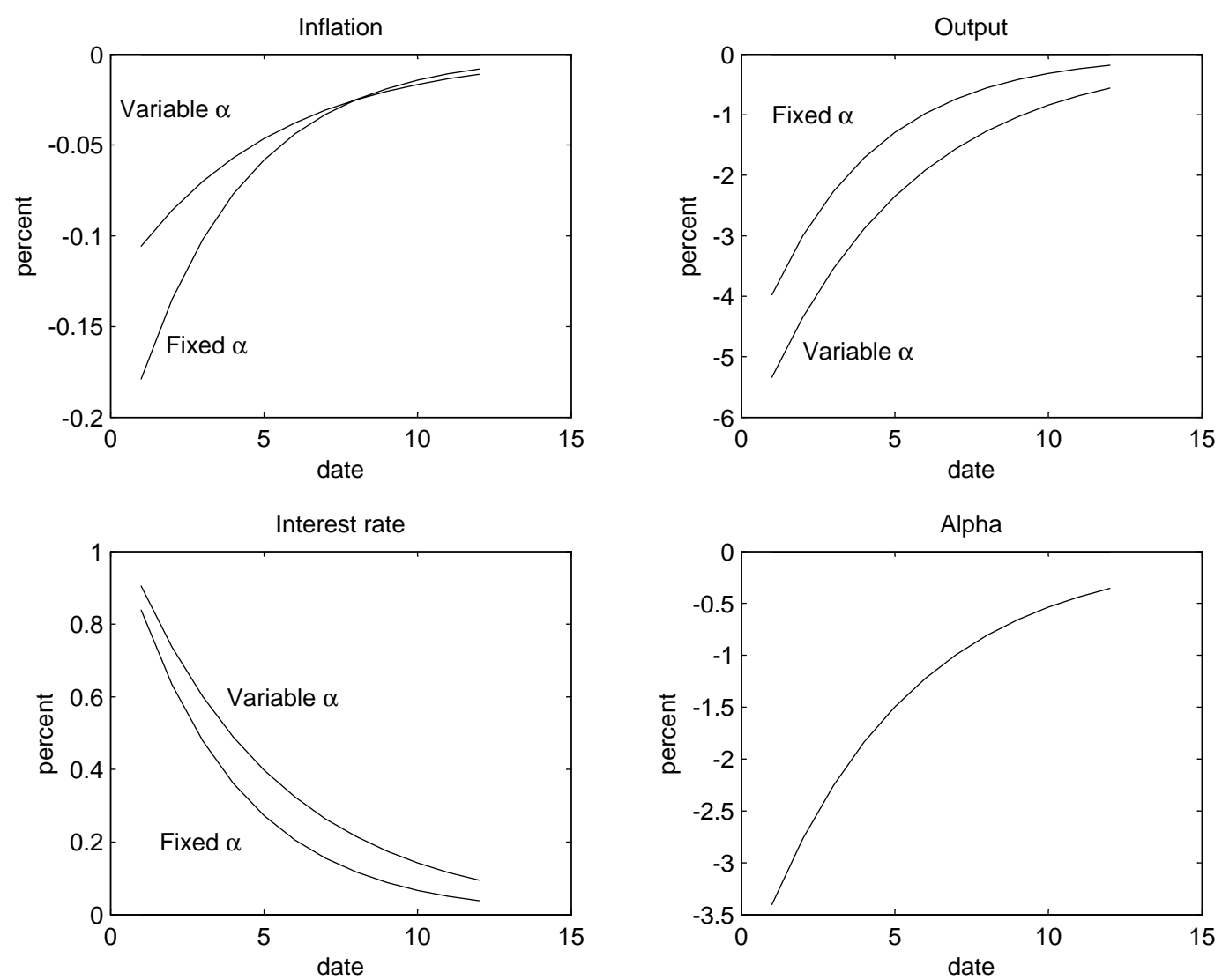
Figure 4: Responses when $\tilde{\alpha}$ responds to $\tilde{x}$ and $\tilde{\pi}, \pi=.012$
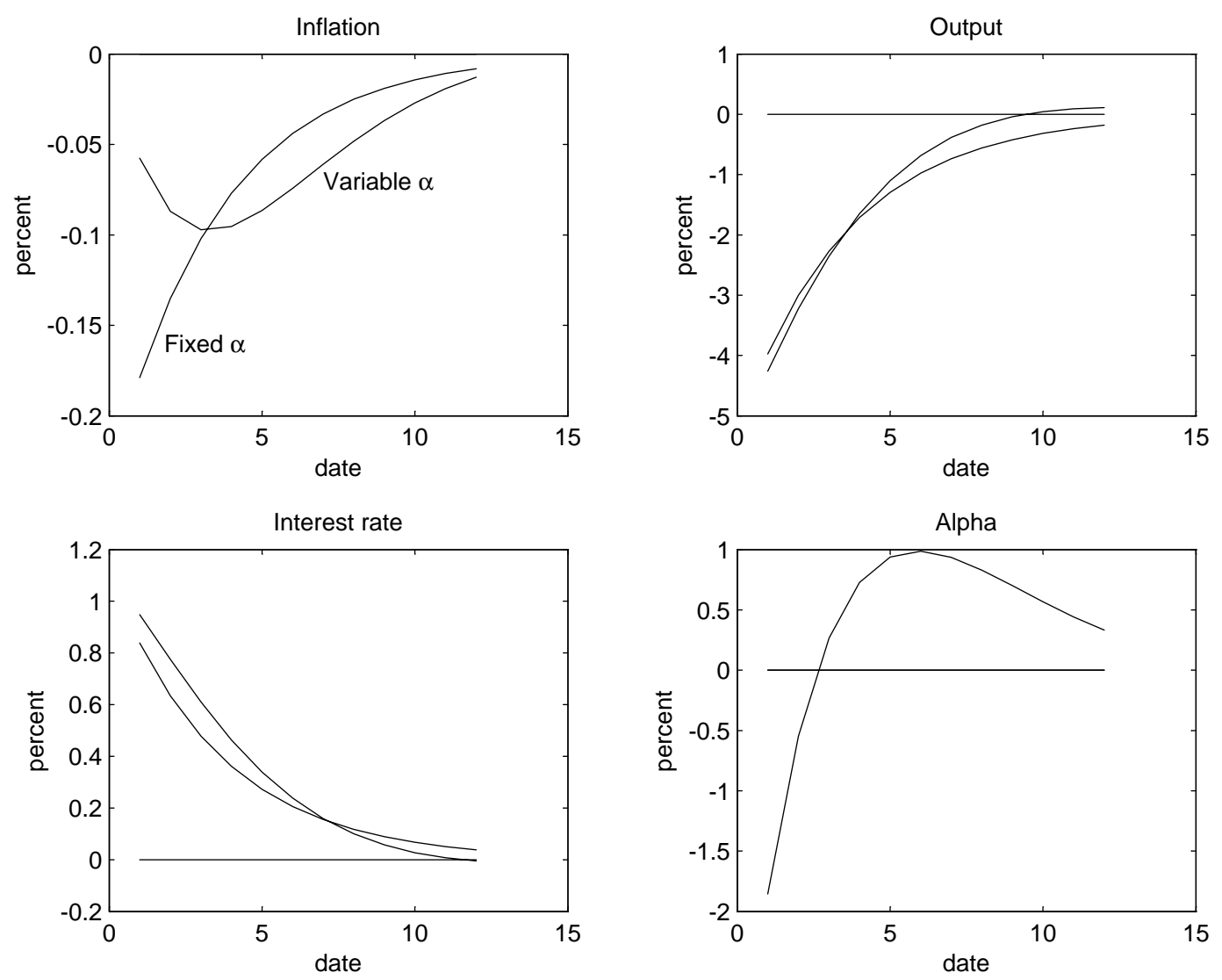
Figure 5: Responses when $\tilde{\alpha}$ responds to $\tilde{x}$ and $\tilde{\pi}, \pi=.107$
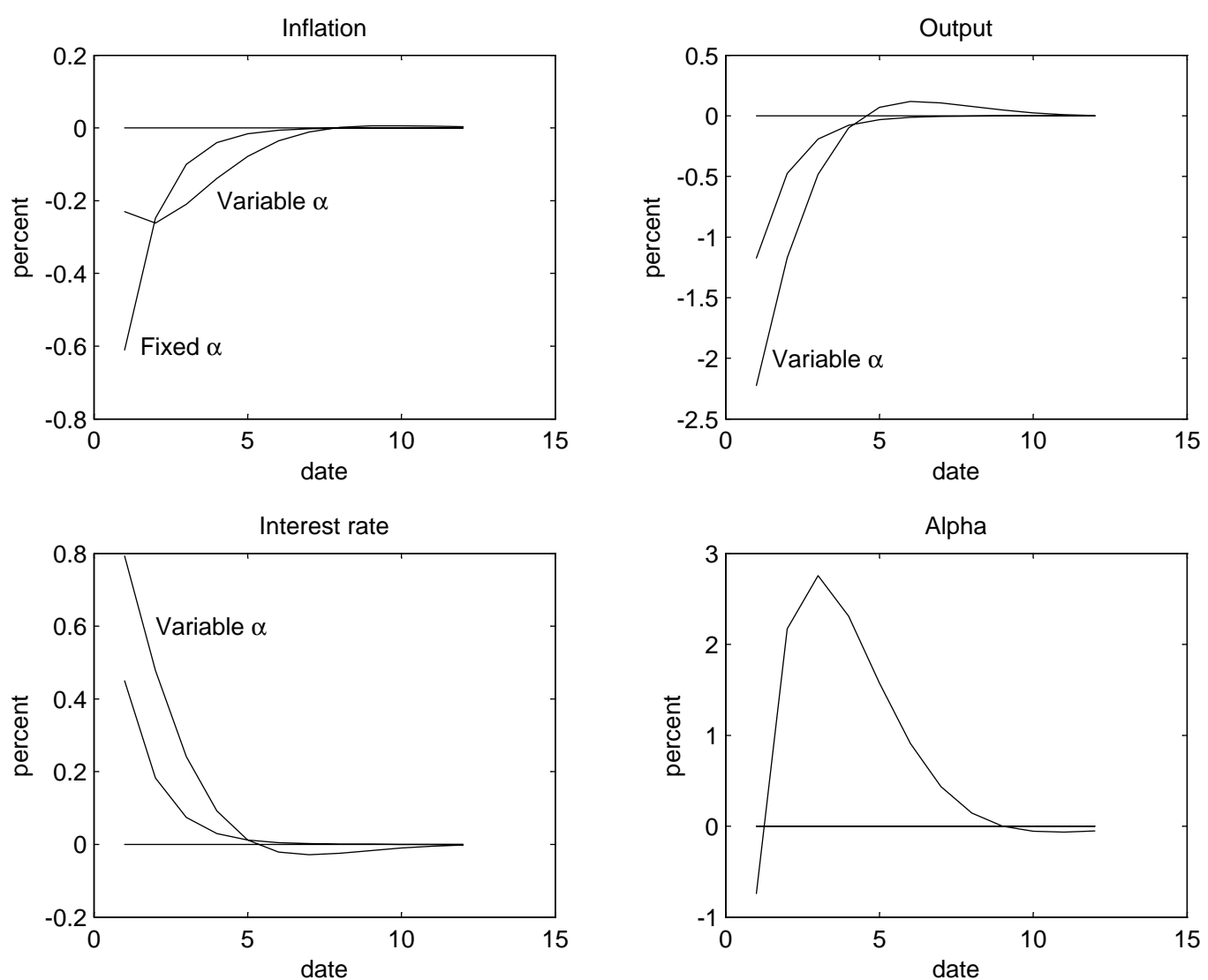
Figure 6: Responses with exogenous $\alpha$
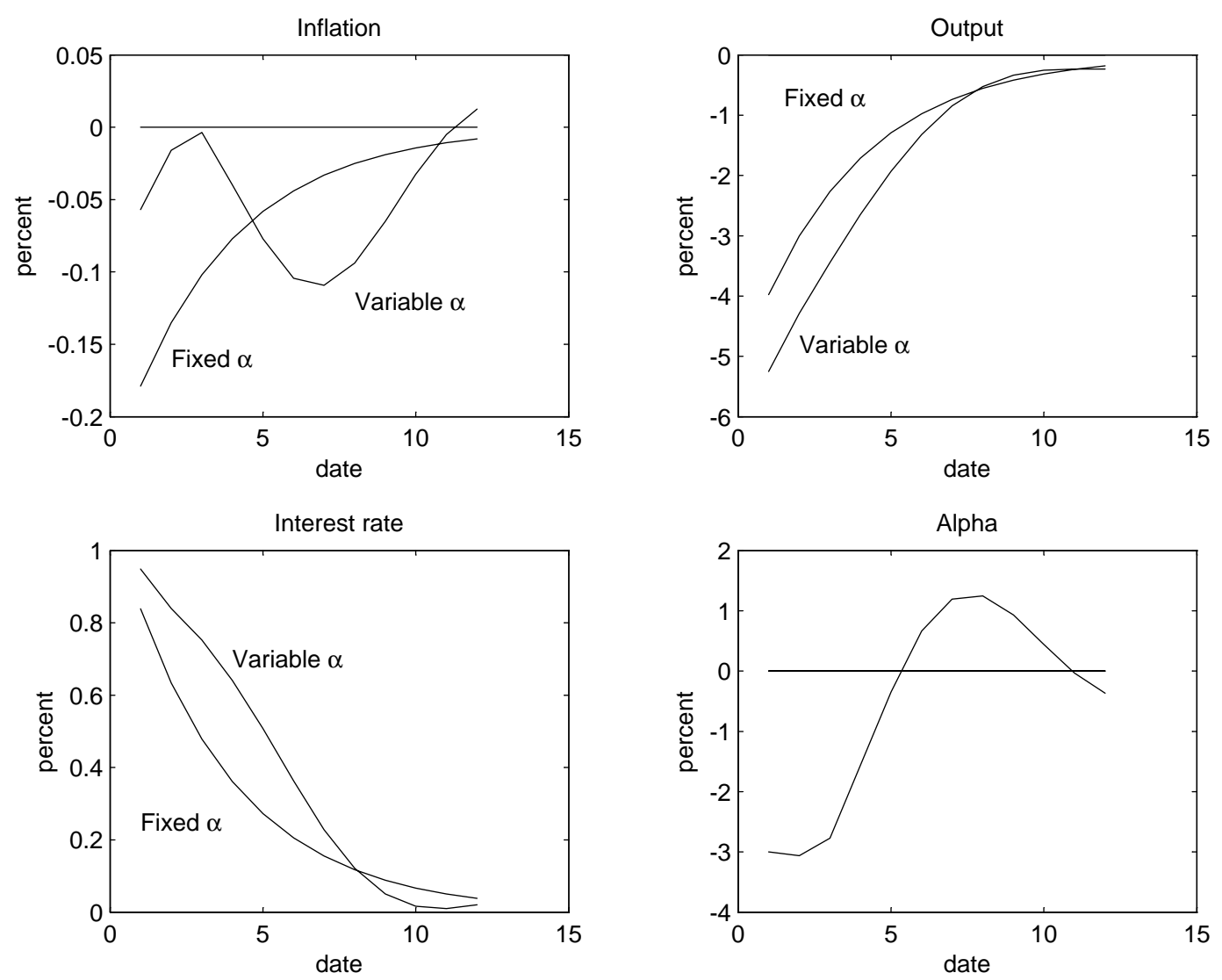
Figure 7: Responses with exogenous $\alpha$ and habit persistence
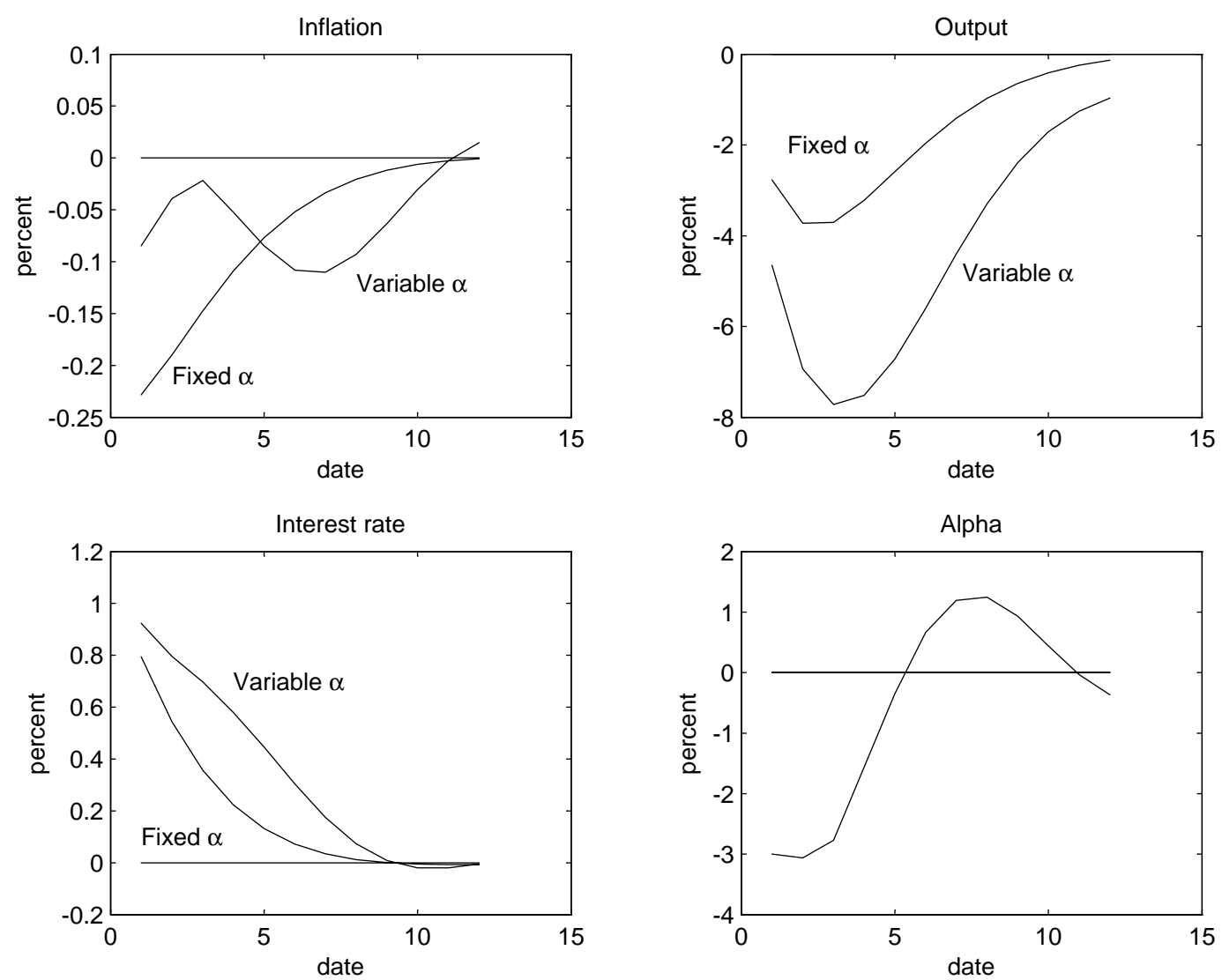